TITLE:

\title{
Characterization of silicon dioxide films on 4H-SiC (0001) Si, (1-100) M, and (11-20) A faces by cathodoluminescence spectroscopy
}

\section{$\operatorname{AUTHOR(S):~}$}

Yoshikawa, M.; Inoue, K.; Seki, H.; Nanen, Y.; Kato, M.; Kimoto, T.

\section{CITATION:}

Yoshikawa, M.... [et al]. Characterization of silicon dioxide films on 4H-SiC (0001) Si, (1-100) $\mathrm{M}$, and (11-20) A faces by cathodoluminescence spectroscopy. Applied Physics Letters 2013, 102(5): 051612.

\section{ISSUE DATE:}

2013-02-08

URL:

http://hdl.handle.net/2433/187954

\section{RIGHT:}

(C) 2013 American Institute of Physics. This article may be downloaded for personal use only. Any other use requires prior permission of the author and the American Institute of Physics. 


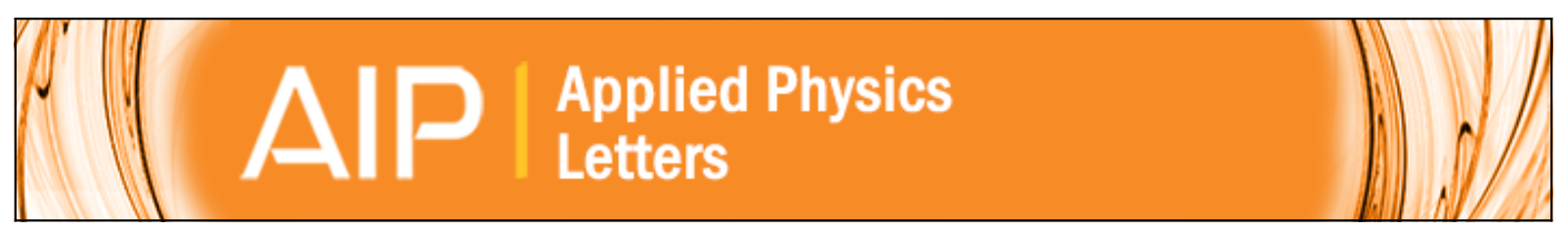

Characterization of silicon dioxide films on $4 \mathrm{H}-\mathrm{SiC}(0001) \mathrm{Si},(1-100) \mathrm{M}$, and (11-20) A faces by cathodoluminescence spectroscopy

M. Yoshikawa, K. Inoue, H. Seki, Y. Nanen, M. Kato, and T. Kimoto

Citation: Applied Physics Letters 102, 051612 (2013); doi: 10.1063/1.4791789

View online: http://dx.doi.org/10.1063/1.4791789

View Table of Contents: http://scitation.aip.org/content/aip/journal/apl/102/5?ver=pdfcov

Published by the AIP Publishing

\section{Articles you may be interested in}

Atomic oxidation of large area epitaxial graphene on $4 \mathrm{H}-\mathrm{SiC}(0001)$

Appl. Phys. Lett. 104, 093109 (2014); 10.1063/1.4867348

Characterization of silicon dioxide films on $4 \mathrm{H}-\mathrm{SiC} \mathrm{Si}(0001)$ face by cathodoluminescence spectroscopy and $\mathrm{x}$ ray photoelectron spectroscopy

Appl. Phys. Lett. 100, 082105 (2012); 10.1063/1.3688173

Thermal and doping dependence of $4 \mathrm{H}-\mathrm{SiC}$ polytype transformation

Appl. Phys. Lett. 81, 2785 (2002); 10.1063/1.1512816

Effects of nitridation in gate oxides grown on $4 \mathrm{H}-\mathrm{SiC}$

J. Appl. Phys. 90, 5058 (2001); 10.1063/1.1412579

Cathodoluminescence measurements of suboxide band-tail and Si dangling bond states at ultrathin Si-SiO 2 interfaces

J. Vac. Sci. Technol. B 16, 2177 (1998); 10.1116/1.590145

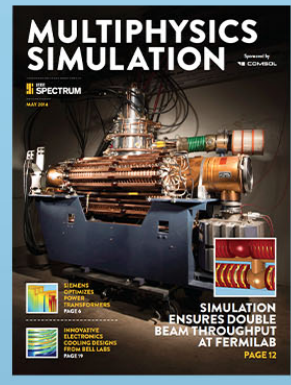

Free online magazine

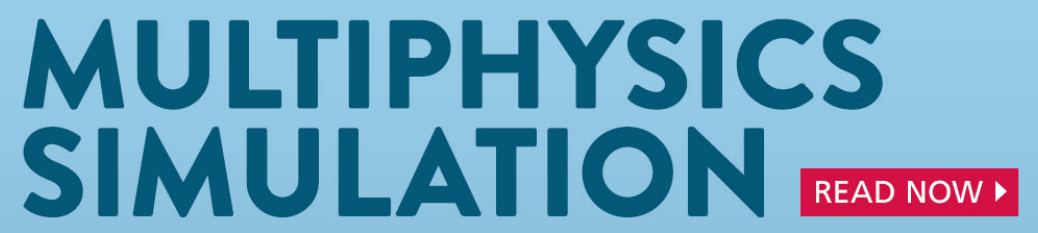




\title{
Characterization of silicon dioxide films on $4 \mathrm{H}-\mathrm{SiC}(0001) \mathrm{Si},(1-100) \mathrm{M}$, and (11-20) A faces by cathodoluminescence spectroscopy
}

\author{
M. Yoshikawa, ${ }^{1, a)}$ K. Inoue, ${ }^{1}$ H. Seki, ${ }^{1}$ Y. Nanen, ${ }^{2}$ M. Kato, ${ }^{2}$ and T. Kimoto ${ }^{2}$ \\ ${ }^{1}$ Toray Research Center Inc., 3-3-7 Sonoyama, Otsu, Shiga 520-8567, Japan \\ ${ }^{2}$ Department of Electronic Science and Engineering, Kyoto University, \\ A1-301 Katsura, Nishikyo, Kyoto 615-8510, Japan
}

(Received 1 December 2012; accepted 29 January 2013; published online 8 February 2013)

We prepared $\mathrm{SiO}_{2}$ films with channel mobilities (CMs) of 35,105 , and $112 \mathrm{~cm}^{2} / \mathrm{Vs}$ on $4 \mathrm{H}-\mathrm{SiC}$ (0001) $\mathrm{Si},(1-100) \mathrm{M}$, and (11-20) A faces by post-oxidation annealing (POA) in NO ambient and measured the cathodoluminescence (CL) spectra. For an acceleration voltage of $5 \mathrm{kV}$, the CL peak assigned to oxygen vacancy centers (OVCs) weakens by POA, whereas the CL peak related to $\mathrm{Si}-\mathrm{N}$ bonding structures intensifies with increasing CM. This suggests that $\mathrm{OVCs}$ in the $\mathrm{SiO}_{2} / \mathrm{SiC}$ interface are terminated by $\mathrm{N}$. We show that $\mathrm{NO}$ ambient POA increases the CM more effectively than that by $\mathrm{N}_{2} \mathrm{O}$ ambient. CL spectroscopy provides us with extensive information on OVCs, non-bridging oxidation hole centers, and dangling bonds in the $\mathrm{SiO}_{2} / \mathrm{SiC}$ interface on $4 \mathrm{H}-\mathrm{SiC}$ substrates and on the CM in n-type MOS capacitors. (C) 2013 American Institute of Physics.

[http://dx.doi.org/10.1063/1.4791789]

The presence native silicon dioxide in silicon carbide, a well-known wide-bandgap semiconductor, means that $\mathrm{SiC}$ is suitable for high-power, high-frequency metal-oxide-semiconductor (MOS) devices. The interface trap densities $\left(D_{\text {it }}\right)$ at the $\mathrm{SiO}_{2} / \mathrm{SiC}$ interface and the effective fixed charge densities $\left(Q_{\text {eff }}\right)$ are one to two orders of magnitude higher than those typically found at the $\mathrm{SiO}_{2} / \mathrm{Si}$ interface (which are of the order of $\left.10^{11} \mathrm{~cm}^{-2}\right) ;{ }^{1}$ these high values degrade the channel mobility $(\mathrm{CM}){ }^{2-5}$ The presence of interface traps in $\mathrm{SiC}$ MOS field-effect transistors (FETs) is attributed to (i) excess carbon, ${ }^{4,6}$ (ii) interface defects due to the presence of threefold coordinated $\mathrm{O}$ and $\mathrm{C}$ interstitial atoms, ${ }^{4,6}$ and (iii) point defects such as $\mathrm{Si}$ and $\mathrm{O}$ vacancies that extend into the underlying $\mathrm{SiC}$; this was determined via a comparison with $\mathrm{SiO}_{2}$ films grown on a $\mathrm{Si}$ substrate. ${ }^{7,8}$ Although postoxidation annealing (POA) by $\mathrm{H}_{2},{ }^{2} \mathrm{NO},{ }^{9,10}$ or $\mathrm{N}_{2} \mathrm{O}^{3,11-13}$ effectively increases the $\mathrm{CM}$, few studies have focused on the effect of POA on the microstructure ${ }^{14,15}$ of $\mathrm{SiO}_{2}$ films on $\mathrm{SiC}$ wafers.

In cathodoluminescence (CL) spectroscopy, luminescence of a sample subjected to electron beam irradiation is observed. ${ }^{16-18} \mathrm{CL}$ spectroscopy provides considerable information on the defects in thin $\mathrm{SiO}_{2}$ films. In a previous study, ${ }^{19}$ we measured the CL spectra of $\mathrm{SiO}_{2}$ films on Si prepared by various methods and observed peaks at 445 and $480 \mathrm{~nm}$, originating from oxygen vacancy centers (OVCs). The CL measurement of the cross section of a thermally grown $\mathrm{SiO}_{2}$ film on a $\mathrm{Si}$ substrate indicated that the intensities of the these peaks in the $\mathrm{SiO}_{2} / \mathrm{Si}$ interface were stronger than that of the CL peak at $640 \mathrm{~nm}$, which was attributed to non-bridging oxidation hole centers (NBOHCs). ${ }^{19}$

We have also measured the CL spectra of $\mathrm{SiO}_{2}$ films grown on $4 \mathrm{H}-\mathrm{SiC}$ wafers ${ }^{20}$ and found that for an acceleration voltage of $5 \mathrm{kV}$, the CL peaks at 460 and $490 \mathrm{~nm}$ assigned to

\footnotetext{
${ }^{\text {a) }}$ Author to whom correspondence should be addressed. Electronic mail: masanobu_yoshikawa@trc.toray.co.jp.
}

OVCs become weak after POA in $\mathrm{N}_{2} \mathrm{O}$ ambient at $1300^{\circ} \mathrm{C}$, whereas the $\mathrm{CL}$ peak around $580 \mathrm{~nm}$ related to $\mathrm{Si}-\mathrm{N}$ bonding structures becomes intense. Furthermore, the peak assigned to $\mathrm{N}-\mathrm{Si}^{3}$ configurations in $\mathrm{X}$-ray photoelectron spectroscopy (XPS) spectra was observed in the $\mathrm{SiO}_{2} / \mathrm{SiC}$ interface only in samples annealed in $\mathrm{N}_{2} \mathrm{O}$ ambient. These results suggested that the $D_{\text {it }}$ decreased and the CM in n-type MOS capacitors increased by the termination of dangling bonds by the $\mathrm{N}$ atom in the $\mathrm{SiO}_{2} / \mathrm{SiC}$ interface. CL spectroscopy and XPS provided us with extensive information on the OVCs and dangling bonds in the $\mathrm{SiO}_{2} / \mathrm{SiC}$ interface on the $4 \mathrm{H}-\mathrm{SiC}$ substrate.

Although it is known that POA in $\mathrm{H}_{2},{ }^{2} \mathrm{NO},{ }^{9,10}$ or $\mathrm{N}_{2} \mathrm{O}^{3,11-13}$ ambient effectively increases $\mathrm{CM}$, few studies have focused on the effect of POA on the microstructure of the $\mathrm{SiO}_{2} / \mathrm{SiC}$ interface on $\mathrm{SiC}$ wafers. We prepared $\mathrm{SiO}_{2}$ films grown on $4 \mathrm{H}-\mathrm{SiC}$ (0001) $\mathrm{Si},(1-100) \mathrm{M}$, and (11-20) A faces by POA in $\mathrm{NO}$ ambient at $1250^{\circ} \mathrm{C}$ and found that the $\mathrm{SiO}_{2}$ film grown on the $4 \mathrm{H}-\mathrm{SiC}(11-20)$ A face had a very large CM of $112 \mathrm{~cm}^{2} / \mathrm{Vs}$. To clarify the origin of this high $\mathrm{CM}$, we studied the changes in the CL spectra of these $\mathrm{SiO}_{2}$ films and clarified the bonding structures near the $\mathrm{SiO}_{2} / \mathrm{SiC}$ interface based on the obtained results.

Epitaxial layers (approximately $5 \mu \mathrm{m}$ thick) were grown by chemical vapor deposition (CVD) on $4^{\circ}$ off-axis (0001) $\mathrm{Si},(1-100) \mathrm{M}$, and (11-20) A faces. ${ }^{21}$ After these layers were RCA cleaned, they were thermally oxidized in dry $\mathrm{O}_{2}$ at $1250^{\circ} \mathrm{C}$ before $\mathrm{POA}$ in $\mathrm{NO}$ ambient at $1250^{\circ} \mathrm{C}$. The samples were then annealed in $\mathrm{Ar}$ ambient at $1250^{\circ} \mathrm{C}$. The typical oxide thickness was approximately $41-47 \mathrm{~nm}$. The $D_{\text {it }}$ values were estimated from high-(1 MHz) and low-frequency (quasi-static) capacitance-voltage $(\mathrm{C}-\mathrm{V})$ curves of n-type MOS capacitors, and the $Q_{\text {eff }}$ values were determined from the flatband voltage in the $\mathrm{C}-\mathrm{V}$ curves. The voltage sweep rate was $0.1 \mathrm{~V} / \mathrm{s}$. The thicknesses, oxidation conditions, as well as the $D_{\mathrm{it}}, Q_{\mathrm{eff}}$, and CM values of the samples are listed in Table I. 
TABLE I. Thickness, oxidation condition, interface trap densities $\left(\boldsymbol{D}_{\mathbf{i t}}\right)$, effective fixed charge densities $\left(\boldsymbol{Q}_{\text {eff }}\right)$, and channel mobility of thermally grown $\operatorname{SiO}{ }_{2}$ films on the $4 \mathrm{H}-\mathrm{SiC}$ (0001) Si, (1-100) M, and (11-20) A faces (we call those samples Si, M, and A, respectively).

\begin{tabular}{|c|c|c|c|c|c|c|}
\hline Face & $\begin{array}{l}\text { Thickness } \\
\text { (nm) }\end{array}$ & $\begin{array}{c}\text { Thermal } \\
\text { oxidation condition }\end{array}$ & $\begin{array}{l}\text { Post-oxidation } \\
\text { annealing condition }\end{array}$ & $\begin{array}{c}D_{\mathrm{it}}\left(\mathrm{cm}^{2} \mathrm{eV}\right)^{-1} \\
\left(\mathrm{E}_{\mathrm{c}}-0.2 \mathrm{eV}\right)\end{array}$ & $\begin{array}{c}Q_{\text {eff }} \\
\left(\mathrm{cm}^{-2}\right)\end{array}$ & $\begin{array}{l}\text { Mobility } \\
\left(\mathrm{cm}^{2} / \mathrm{Vs}\right)\end{array}$ \\
\hline $\mathrm{Si}$ & 41 & $1250^{\circ} \mathrm{C} 60 \mathrm{~min}$ & $\mathrm{NO}$ anneal $1250^{\circ} \mathrm{C}, 60 \mathrm{~min} \mathrm{Ar}$ anneal $1250^{\circ} \mathrm{C}, 60 \mathrm{~min}$ & $5.0 \times 10^{11}$ & $1.5 \times 10^{11}$ & 35 \\
\hline A & 47 & $1250^{\circ} \mathrm{C} 10 \mathrm{~min}$ & $\mathrm{NO}$ anneal $1250^{\circ} \mathrm{C}, 60 \mathrm{~min} \mathrm{Ar}$ anneal $1250^{\circ} \mathrm{C}, 60 \mathrm{~min}$ & $3.4 \times 10^{11}$ & $1.8 \times 10^{11}$ & 112 \\
\hline M & 45 & $1250^{\circ} \mathrm{C} 10 \mathrm{~min}$ & $\mathrm{NO}$ anneal $1250^{\circ} \mathrm{C}, 60 \mathrm{~min} \mathrm{Ar}$ anneal $1250^{\circ} \mathrm{C}, 60 \mathrm{~min}$ & $3.6 \times 10^{11}$ & $1.7 \times 10^{11}$ & 105 \\
\hline
\end{tabular}

We used a scanning electron microscope (SEM) with a Schottky-emission-type gun (HITACHI S-4300SE) as the excitation source for the CL measurements. ${ }^{20}$ The $\mathrm{CL}$ signals were collected by an ellipsoidal mirror and optical fiber and detected using a Jobin Yvon HR-320 single monochromator equipped with a charge coupled device (CCD). We recorded the CL spectra at acceleration voltages of 3 and $5 \mathrm{kV}$ at room temperature with a beam current of less than $5 \mathrm{nA} .^{22}$ To minimize the degradation caused by electron beam irradiation, most CL spectra were measured for $60 \mathrm{~s}$. We repeated the CL measurements of each film three times and obtained reproducible CL spectra. The CL peaks from the optical fiber that was used for a detection of the CL spectra were not observed in our CL system. ${ }^{19,20,22}$

Figure 1 shows the $\mathrm{CL}$ spectra of the $\mathrm{SiO}_{2}$ films grown on the $4 \mathrm{H}-\mathrm{SiC}$ (0001) Si, (1-100) M, and (11-20) A faces (we refer to these as samples $\mathrm{Si}, \mathrm{M}$, and $\mathrm{A}$, respectively) measured at $3 \mathrm{kV}$. CL peaks were observed at 460,490 , and $640 \mathrm{~nm}$ for the $\mathrm{SiO}_{2}$ films on the $4 \mathrm{H}-\mathrm{SiC}$ substrates. The peak and dip in Fig. 1 at around $900 \mathrm{~nm}$ are caused by a combination of the overtone by the CL peak at around $500 \mathrm{~nm}$ and absorption of the emitted CL by the optical fiber. The CL peaks at 460 and $490 \mathrm{~nm}$ were attributed to OVCs, whereas the CL peak at $640 \mathrm{~nm}$ was attributed to NBOHCs. ${ }^{20,22}$ The CL peaks at 390 and $540 \mathrm{~nm}$ originate from a bound exciton and donor-acceptor pair by the $4 \mathrm{H}-$ $\mathrm{SiC}$ substrates, respectively. The weak CL peak at around $280 \mathrm{~nm}$ is considered to originate from OVCs. ${ }^{19}$

Figure 2 shows the $\mathrm{CL}$ spectra of the $\mathrm{SiO}_{2}$ films for samples $\mathrm{Si}, \mathrm{M}$, and $\mathrm{A}$, measured at $5 \mathrm{kV}$. As shown in Figs. 1 and 2, the CL peaks at around 460 and $490 \mathrm{~nm}$ are observed strongly when measured at $3 \mathrm{kV}$, whereas the $\mathrm{CL}$ peak around $580 \mathrm{~nm}$ for all the samples is observed strongly when measured at $5 \mathrm{kV}$.

In a previous paper, ${ }^{20}$ we measured the $\mathrm{CL}$ spectra of $\mathrm{SiO}_{2}$ films grown on the $4 \mathrm{H}-\mathrm{SiC}(0001) \mathrm{Si}$ face and found that

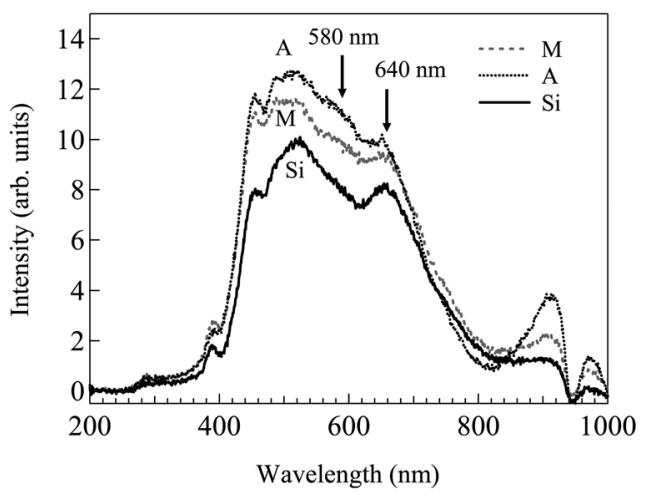

FIG. 1. CL spectra of $\mathrm{SiO}_{2}$ films on the $4 \mathrm{H}-\mathrm{SiC}$ (0001) $\mathrm{Si}$, (1-100) M, and (11-20) A faces measured at acceleration voltages of $3 \mathrm{kV}$. for $5 \mathrm{kV}$, the CL peaks at 460 and $490 \mathrm{~nm}$, assigned to OVCs, become weak after POA in $\mathrm{N}_{2} \mathrm{O}$ ambient at $1300^{\circ} \mathrm{C}$, whereas the CL peak at around $580 \mathrm{~nm}$, related to $\mathrm{Si}-\mathrm{N}$ bonding structures, becomes intense. Furthermore, the peak assigned to $\mathrm{N}-\mathrm{Si}^{3}$ configurations in XPS spectra was observed in the $\mathrm{SiO}_{2} /$ $\mathrm{SiC}$ interface only in samples annealed in $\mathrm{N}_{2} \mathrm{O}$ ambient. Based upon the results of the previous paper ${ }^{20}{ }^{2}$ we concluded that the $\mathrm{CL}$ peak at $580 \mathrm{~nm}$ for all the samples here could be assigned to $\mathrm{Si}-\mathrm{N}$ bonding structures. The CL peaks at $580 \mathrm{~nm}$ cannot be assigned to the second order transition of the weak CL peaks at $280 \mathrm{~nm}$, because the second order peak is generally weaker than the first order one.

A comparison between Figs. 1 and 2 indicates that for all the samples, the CL peak at $460 \mathrm{~nm}$, which is assigned to OVCs, is stronger at $3 \mathrm{kV}$ than at $5 \mathrm{kV}$, whereas the CL peak at $580 \mathrm{~nm}$, which is assigned to $\mathrm{Si}-\mathrm{N}$ bonding structures, is stronger at $5 \mathrm{kV}$ than at $3 \mathrm{kV}$. Monte Carlo simulations indicated that the penetration depths of electrons in thin $\mathrm{SiO}_{2}$ films at 3 and $5 \mathrm{kV}$ were approximately 30 and $60 \mathrm{~nm}$, respectively. By comparing the penetration depth and sample thickness, the intensity of the CL peak at $580 \mathrm{~nm}$ normalized by that of the CL peak at $460 \mathrm{~nm}$ is considered to increase in the $\mathrm{SiO}_{2} / \mathrm{SiC}$ interface. This suggests that OVCs in the $\mathrm{SiO}_{2} /$ $\mathrm{SiC}$ interface are terminated by $\mathrm{N}$ after POA in $\mathrm{NO}$ ambient at $1250^{\circ} \mathrm{C}$.

The CL spectra of the $\mathrm{SiO}_{2}$ films were decomposed into six CL peaks with Gaussian line shapes. ${ }^{19,23}$ Figures 3(a) and 3(b) show the CL spectra obtained by fitting the Gaussian line shapes to the CL spectra for samples $\mathrm{Si}, \mathrm{M}$, and $\mathrm{A}$, measured at 3 and $5 \mathrm{kV}$. As seen in Figs. 3(a) and 3(b), the experimental spectra agree well with the composed one. The decomposed peak at $760 \mathrm{~nm}$ might originate from the second order transition of the CL peaks at $390 \mathrm{~nm}$.

Figures 4(a) and 4(b) show the relationship between the $\mathrm{CM}$ of the SiC-MOSFET and the relative CL intensity at

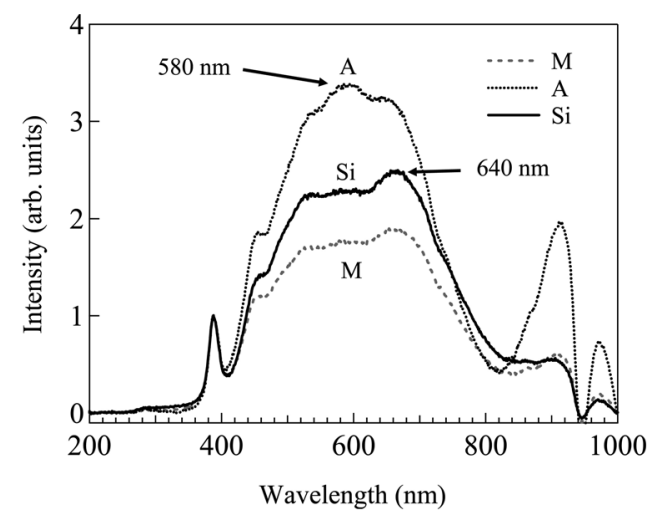

FIG. 2. CL spectra of $\mathrm{SiO}_{2}$ films on the $4 \mathrm{H}-\mathrm{SiC}$ (0001) $\mathrm{Si}$, (1-100) M, and (11-20) A faces measured at acceleration voltages of $5 \mathrm{kV}$. 


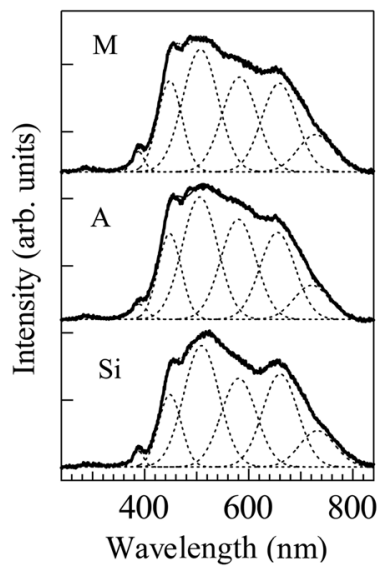

(a) $3 \mathrm{kV}$

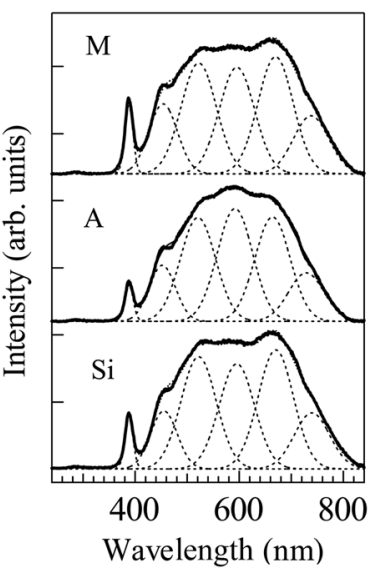

(b) $5 \mathrm{kV}$
FIG. 3. CL spectra of $\mathrm{SiO}_{2}$ films on the $4 \mathrm{H}-\mathrm{SiC}(0001) \mathrm{Si}$, (1-100) M, and (11-20) A faces decomposed into six CL peaks with Gaussian line shapes: (a) 3 and (b) $5 \mathrm{kV}$. The heavy and solid lines show the experimental and spectra composed by each CL peak decomposed by fitting the Gaussian line shapes to the CL spectra, respectively. The dotted line shows each CL peak decomposed by fitting the Gaussian line shapes to the CL spectra.

$580 \mathrm{~nm}$, normalized by that at $460 \mathrm{~nm}$, determined by fitting the Gaussian line shapes to the CL spectra measured at 3 and $5 \mathrm{kV}$, respectively. As shown in these figures, for sample A with the highest $\mathrm{CM}$ of $112 \mathrm{~cm}^{2} / \mathrm{Vs}$, the relative intensity is stronger at $5 \mathrm{kV}$ than at $3 \mathrm{kV}$. This shows that the POA decreased the number of OVCs by $\mathrm{N}$ termination.

Figures 5(a) and 5(b) show the relationship between the $\mathrm{CM}$ of the SiC-MOSFET and the relative CL intensity at $580 \mathrm{~nm}$, normalized by that at $640 \mathrm{~nm}$, measured at 3 and $5 \mathrm{kV}$, respectively. As shown in Fig. 5, the relative intensity increases in strength in the order of sample $\mathrm{Si}, \mathrm{M}$, and $\mathrm{A}$ at 3 and $5 \mathrm{kV}$. This shows that the POA decreased the number of NBOHCs by $\mathrm{N}$ termination in the $\mathrm{SiO}_{2} / \mathrm{SiC}$ interface in the order of sample Si, M, and A. A comparison between Figs. 4 and 5 suggests that the $\mathrm{NO}$ ambient POA tends to decrease the number of OVCs more effectively than NBOHCs in the $\mathrm{SiO}_{2} / \mathrm{SiC}$ interface.

We previously measured the CL spectra of $\mathrm{SiO}_{2}$ films with a CM of $34 \mathrm{~cm}^{2} / \mathrm{Vs}$ grown on the $4 \mathrm{H}-\mathrm{SiC} \mathrm{Si}(0001)$ face substrate by $\mathrm{POA}$ in $\mathrm{N}_{2} \mathrm{O}$ ambient at $1300^{\circ} \mathrm{C}$ and found that the POA decreased the interface trap densities and increased the CM in n-type MOS capacitors by terminating dangling bonds by $\mathrm{N}$ in the $\mathrm{SiO}_{2} / \mathrm{SiC}$ interface. From a com-

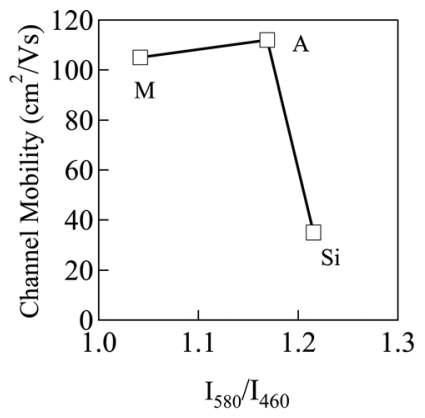

(a) $3 \mathrm{kV}$

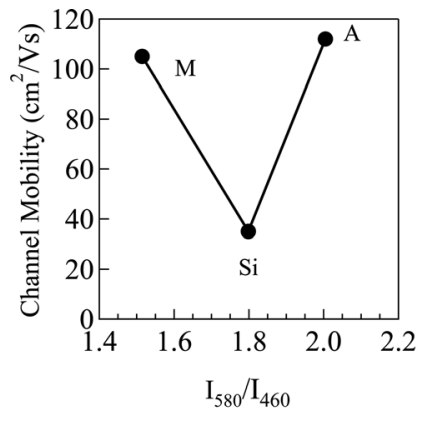

(b) $5 \mathrm{kV}$
FIG. 4. Relation between the CM of the SiC-MOSFET and the CL relative intensity at $580 \mathrm{~nm}$, normalized by that of $460 \mathrm{~nm}$, measured at an acceleration voltage of (a) 3 and (b) $5 \mathrm{kV}$.

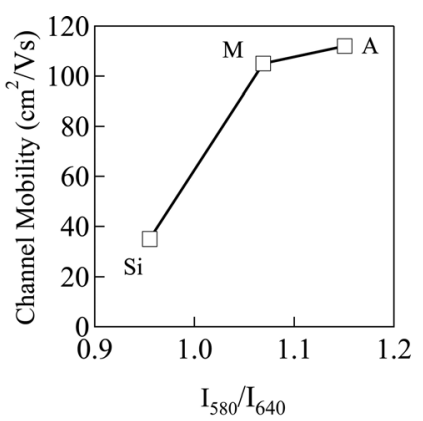

(a) $3 \mathrm{kV}$

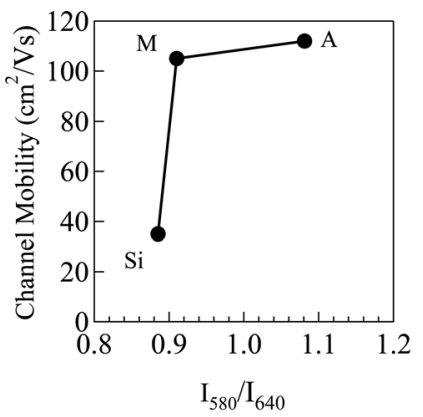

(b) $5 \mathrm{kV}$
FIG. 5. Relation between the CM of the SiC-MOSFET and the CL relative intensity at $580 \mathrm{~nm}$, normalized by that of $640 \mathrm{~nm}$, measured at an acceleration voltage of (a) 3 and (b) $5 \mathrm{kV}$.

parison between the previously measured CMs and those in this work, we concluded that the POA in NO ambient at $1250^{\circ} \mathrm{C}$ decreased the number of OVCs by termination by $\mathrm{N}$ in the $\mathrm{SiO}_{2} / \mathrm{SiC}$ interface and that the POA in $\mathrm{NO}$ ambient increases the CM more effectively than that in $\mathrm{N}_{2} \mathrm{O}$ ambient. $\mathrm{CL}$ spectroscopy provides us with extensive information on OVCs, NBOHCs, and dangling bonds in the $\mathrm{SiO}_{2} / \mathrm{SiC}$ interface on $4 \mathrm{H}-\mathrm{SiC}$ substrates and on the CM in n-type MOS capacitors.

In summary, we have measured the CL spectra of $\mathrm{SiO}_{2}$ films grown on $4 \mathrm{H}-\mathrm{SiC}$ (0001) Si, (1-100) M, and (11-20) A faces and found that for $5 \mathrm{kV}$, the CL peak at $460 \mathrm{~nm}$, assigned to OVCs, became weak by POA in NO ambient at $1250^{\circ} \mathrm{C}$, whereas the $\mathrm{CL}$ peak at around $580 \mathrm{~nm}$, related to $\mathrm{Si}-\mathrm{N}$ bonding structures, became intense, increasing in the order of $\mathrm{SiO}_{2}$ films grown on $4 \mathrm{H}-\mathrm{SiC}$ (0001) $\mathrm{Si}$, (1-100) M, and (11-20) A faces. This suggests that OVCs in the $\mathrm{SiO}_{2} /$ $\mathrm{SiC}$ interface are terminated by $\mathrm{N}$ by $\mathrm{NO}$ ambient POA. From a comparison between the CMs in previous work and this work, we concluded that the NO ambient POA decreased the number of OVCs in the $\mathrm{SiO}_{2} / \mathrm{SiC}$ interface by $\mathrm{N}$ termination and that the NO ambient POA increases the $\mathrm{CM}$ more effectively than that in $\mathrm{N}_{2} \mathrm{O}$ ambient. CL spectroscopy provides us with extensive information on OVCs, NBOHCs, and dangling bonds in the $\mathrm{SiO}_{2} / \mathrm{SiC}$ interface on $4 \mathrm{H}-\mathrm{SiC}$ substrates and on the CM in n-type MOS capacitors.

${ }^{1}$ S. M. Sze, Semiconductor Devices, Physics and Technology, 2nd Ed. (Wiley, 2002), Chap. 6, p. 182.

${ }^{2}$ K. Fukuda, M. Kato, K. Kojima, and J. Senzaki, Appl. Phys. Lett. 84, 2088 (2004).

${ }^{3}$ T. Kimoto, Y. Kanzaki, M. Noborio, H. Kawano, and H. Matsunami, Jpn. J. Appl. Phys., Part 1 44, 1213 (2005).

${ }^{4}$ V. V. Afanasev, M. Bassler, G. Pensl, and M. Schulz, Phys. Status Solidi A 162, 321 (1997).

${ }^{5}$ J. A. Cosper, Jr., Phys. Status Solidi A 162, 305 (1997).

${ }^{6}$ T. Zheleva, A. Lelis, G. Duscher, F. Liu, I. Levin, and M. Das, Appl. Phys. Lett. 93, 022108 (2008).

${ }^{7}$ T. Y. Luo, M. Laughery, G. A. Brown, H. N. Al-Shareef, V. H. C. Watt, A. Karamcheti, M. D. Jackson, and H. R. Huff, Electron Device Lett. 21, 382 (2000).

${ }^{8}$ N. Nagai, K. Terada, Y. Muraji, H. Hashimoto, T. Maeda, Y. Maeda, E. Tahara, N. Tokai, and A. Hatta, J. Appl. Phys. 87, 4747 (2002).

${ }^{9}$ H. J. von Bardeleben, J. L. Cantin, I. C. Vickridge, Y. Song, S. Dhar, L. C. Feldman, J. R. Williams, L. Ke, Y. Shishkin, R. P. Devaty, and W. J. Choyke, Mater. Sci. Forum 483-485, 277 (2005).

${ }^{10}$ P. Jamet, S. Dimitrijer, and P. Tanner, J. Appl. Phys. 90, 5058 (2001).

${ }^{11}$ L. A. Lipkin, M. K. Das, and J. W. Palmour, Mater. Sci. Forum 389-393, 985 (2002). 
${ }^{12}$ Y. Kanzaki, H. Kinbara, H. Kosugi, J. Suda, T. Kimoto, and H. Matsunami, Mater. Sci. Forum 457-460, 1429 (2004).

${ }^{13}$ M. K. Das, Mater. Sci. Forum 457-460, 1275 (2004).

${ }^{14}$ M. Yoshikawa and N. Nagai, Handbook of Vibrational Spectroscopy, edited by J. M. Chalmers and P. R. Griffiths (Wiley, Chichester, 2002), p. 2593.

${ }^{15}$ F. L. Galeener, R. A. Barrio, E. Martinez, and R. J. Elliott, Phys. Rev. Lett. 17, 2429 (1984).

${ }^{16}$ R. G. Yacobi and D. B. Holt, Cathodoluminescence Microscopy of Inorganic Solids (Plenum, New York, 1990).

${ }^{17}$ M. Yoshikawa, K. Iwagami, and H. Ishida, J. Appl. Phys. 51, 1693 (1998).
${ }^{18}$ M. Yoshikawa, M. Murakami, H. Ishida, and H. Harima, Appl. Phys. Lett. 94, 131908 (2009).

${ }^{19}$ M. Yoshikawa, K. Matsuda, Y. Yamaguchi, T. Matsunobe, Y. Nagasawa, H. Fujino, and T. Yamane, J. Appl. Phys. 92, 7153 (2002).

${ }^{20}$ M. Yoshikawa, S. Ogawa, K. Inoue, H. Seki, Y. Tanahashi, H. Sako, Y. Nanen, M. Kato, and T. Kimoto, Appl. Phys. Lett. 100, 082105 (2012).

${ }^{21}$ T. Kimoto, A.Itoh, and H. Matsunami, Phys. Status Solidi B 202, 247 (1997).

${ }^{22}$ M. Yoshikawa, H. Seki, K. Inoue, K. Matsuda, Y. Tanahashi, H. Sako, Y. Nanen, M. Kato, and T. Kimoto, Appl. Spectrosc. 65, 543 (2011).

${ }^{23}$ J. Fournier, P. Grua, J. Néauport, E. Fargin, V. Jubera, D. Talaga, A. Del Guerzo, G. Raffy, and S. Jouannigot, Opt. Mater. Express 3, 1 (2013). 